\title{
MySpace and Facebook: Applying the Uses and Gratifications Theory to Exploring Friend-Networking Sites
}

\author{
JOHN RAACKE, Ph.D. and JENNIFER BONDS-RAACKE, Ph.D.
}

\begin{abstract}
The increased use of the Internet as a new tool in communication has changed the way people interact. This fact is even more evident in the recent development and use of friend-networking sites. However, no research has evaluated these sites and their impact on college students. Therefore, the present study was conducted to evaluate: (a) why people use these friend-networking sites, (b) what the characteristics are of the typical college user, and (c) what uses and gratifications are met by using these sites. Results indicated that the vast majority of college students are using these friend-networking sites for a significant portion of their day for reasons such as making new friends and locating old friends. Additionally, both men and women of traditional college age are equally engaging in this form of online communication with this result holding true for nearly all ethnic groups. Finally, results showed that many uses and gratifications are met by users (e.g., "keeping in touch with friends"). Results are discussed in light of the impact that friend-networking sites have on communication and social needs of college students.
\end{abstract}

\section{INTRODUCTION}

A LTHOUGH THE INTERNET originated in the United States, its use has spread quickly throughout the world. In the mid-1990s, the vast majority (nearly $70 \%$ ) of Internet users resided in North America. However, by 2005, that number was estimated to have dropped to $30 \% .{ }^{1}$ During this time, the Internet had grown in its use, the amount of information available, and its online communication capabilities. ${ }^{2}$ Recent research has begun to focus on the way the Internet is used with regard to relationship building. Research has shown that online communication fosters relationship building, improving communication between parties, ${ }^{3}$ and consistently documents both sex and generational differences in online communication. For example, women are more likely to engage in online communication to maintain personal connections with family, friends, and coworkers, whereas men use online communication for pursuing sexual interests and romance. ${ }^{4}$ In terms of generational differences, young adults spend more time using online communication and are more comfortable doing so as compared to older generations. 5,6

Recently, a new means of online communication has emerged with its own set of idiosyncrasies. This new communication style occurs through the use of social networking sites. Social networking sites are virtual places that cater to a specific population in which people of similar interest gather to communicate, share, and discuss ideas. One specific type of social networking site that has seen an increase in activity is the friend-networking site, such as My-

Department of Psychology and Counseling, University of North Carolina-Pembroke, Pembroke, North Carolina. 
Space and Facebook. ${ }^{6}$ MySpace and Facebook are two friend-networking sites that have become extremely popular among high school and college students. It has been estimated that MySpace has over 20 million registered users, with a sign-up rate of over 230,000 users per day, ${ }^{7}$ and Facebook was estimated to have approximately 9.5 million users as of September 2006. ${ }^{8}$ These networking sites have a number of features that allow individuals to communicate with others. For example, these sites allow users to post information about themselves, post pictures, leave messages for friends about upcoming events, and link (i.e., provide a hyperlink) their sites to friends' sites. Therefore, these sites allow for a varying amount of flexibility in communication style. ${ }^{9}$

Surprisingly, peer-reviewed published research evaluating the impact of these friend-networking sites on behavior is scarce at best. Only one study ${ }^{10}$ has evaluated the impact of friend-networking sites on users. This study assessed the impact of friendnetworking sites (i.e., MySpace and Facebook) on adolescent well-being. Results showed the more an adolescent frequented friend-networking sites, the greater the likelihood his or her social well-being was impacted by information received from that site (by way of posted messages from other users). However, research is needed to examine these friend-networking sites for numerous reasons. First, research needs to be conducted to document the prevalence of these Web sites among college students. Second, research is needed to investigate the characteristics of the typical user of friend-networking sites (e.g., sex, age, ethnicity). Finally, the personal and social needs individuals are obtaining from using these friend-networking sites should be explored.

One way to explore the needs individuals are meeting by using friend-networking sites is to apply the uses and gratification theory (previously applied to using the Internet in general $\left.{ }^{11}\right)$. The uses and gratifications theory is concerned with how individuals use the media (in this case, friend-networking sites), and therefore it emphasizes the importance of the individual. There are criticisms of the uses and gratifications theory ${ }^{13-18}$ (e.g., failure to integrate separate research findings). However, researchers from the uses and gratifications camp have responded to these criticisms by highlighting the recently developed methodologically oriented line of research that draws a distinction between concepts that are antecedents to behavior (e.g., uses and gratifications sought) and those that are consequents of behavior (e.g., gratifications obtained). ${ }^{12}$

Therefore, the purpose of the present study was threefold. One, general information regarding the prevalence of the use of friend-networking sites among college students was obtained. For example, researchers evaluated how much time students spend on these sites and how much effort they put into their accounts. Two, information regarding characteristics about the users of these sites was obtained (e.g., sex, age, and ethnicity). Finally, the researchers evaluated these friend-networking sites using the uses and gratifications theory. Specifically, two of the current directions under this theory-effectiveness of different media (or content) to meet an individual's needs and the background of the individual (e.g., demographic variables) - were evaluated for both uses and gratifications of having a friend-networking account, as well as failed uses and gratifications for not having a friend-networking account.

\section{METHOD}

\section{Participants}

One hundred sixteen students from a 4-year public, East Coast university were recruited to participate in this study on student Internet usage, with no mention made of friend-networking sites. Of the participants, $53(45.7 \%)$ were men and $63(54.3 \%)$ were women, with a mean age of 19.7 years $(S D=$ 3.7). In addition, of the participants, $55(47.4 \%)$ were Caucasian, 25 (21.6\%) were African American, 18 $(15.5 \%)$ were Native American, 10 (8.6\%) were multiracial, and $8(6.9 \%)$ were of Hispanic origin.

\section{Materials and procedure}

Upon arriving to the study, participants were given a two-part packet to complete. The first page contained only one question, "Do you have a MySpace or Facebook account?" Students responded by checking yes or no to this question. Directions then instructed those participants who had checked yes to proceed to page 2 of the packet (Part I) and those who checked no to proceed to page 5 of the packet (Part II).

Part I of the packet, completed by students having either a MySpace or Facebook account, contained four sections. Section 1 asked participants general information about their accounts. For example, participants were asked about what type of accounts they had and how long they had them. In section 2, participants were asked to indicate what uses and gratifications they obtained from using these friend-networking sites, such as "to keep in touch with current friends" and "to make new friends." In section 3, participants were asked to 
predict why other students would not have a MySpace or Facebook account. Sample failed uses and gratifications were "they do not have any friends" and "they do not want to keep in touch." The final section of Part I collected demographic information, including sex, age, and ethnicity.

Part II of the packet, completed by students not having either a MySpace or Facebook account, also contained four sections. Section 1 asked participants general information about why they did not have a MySpace or Facebook account. For example, participants were asked if they had heard of these sites before and if these sites were popular among their friends. Section 2 had participants indicate failed uses and gratifications for not having a friend-networking site. Failed uses and gratifications included "I have not made many friends yet" and "I feel intimidated." In section 3, participants predicted uses and gratifications for individuals having a friendnetworking account. Specifically, participants were asked to predict why other students would have a MySpace or Facebook account. Sample uses and gratifications were "to keep in touch with friends/meet new people" and "to occupy time." The final section of Part II collected demographic information, including sex, age, and ethnicity.

\section{RESULTS}

This section is organized according to the results pertaining to participants who currently had either a MySpace or Facebook account (referred to as users) and the results pertaining to participants who did not have an account at either site (nonusers).

\section{Users: general information}

Of participants surveyed, 101 or $87.1 \%$ (49 men and 52 women) indicated having either a MySpace or Facebook account. Of the participants who had accounts, 84 (83.2\%) had MySpace accounts, 91 (90.1\%) had Facebook accounts, and 75 (74.3\%) had accounts at both sites. Over $70 \%$ of participants had their accounts for 7 months to 24 months. On an average day, users reported spending 1.46 hours on their accounts and 1.10 hours on others' accounts. Users also reported logging into their account an average of 4.19 times per day. A large percentage of users $(87.1 \%)$ made information about themselves (e.g., age, sex, physical description) available on their Web site. Only $51.5 \%$ of users set their Web sites to private (requiring others to request permission to view the contents). However, only $12.9 \%$ of users posted their schedules on their accounts.
When asked to rate on a 7-point Likert scale from 1 , never, to 7, constantly, how often they changed the appearance of their Web site and how often they updated the Web sites, the means were 2.83 and 2.98 respectively. Participants were also asked how many friends they had linked to the account. The mean number of friends linked was 235.51 (the mode and median were 200). On follow-up questions regarding friends, $52.5 \%$ of participants knew all their friends linked to their accounts, and $79.2 \%$ of participants had additional friends who did not have a MySpace or Facebook account. In general, participants responded feeling somewhat happy (mean of 4.81 on 7-point Likert scale from 1, not at all happy, to 7, very happy) and somewhat excited (mean of 4.56 on a 7-point Likert scale from 1, not at all excited, to 7, very excited) about receiving new messages on their accounts.

\section{Users: uses and gratifications}

Very popular uses and gratification for having either account included "to keep in touch with old friends" $(96.0 \%)$, "to keep in touch with current friends" (91.1\%), "to post/look at pictures" (57.4\%), "to make new friends" (56.4\%), and "to locate old friends" (54.5\%). Less commonly reported uses and gratifications included "to learn about events" $(33.7 \%)$, "to post social functions" (21.8\%), "to feel connected" (19.8\%), "to share information about yourself" (13.9), "for academic purposes" (10.9\%), and "for dating purposes" (7.9\%).

When asked to predict why other people did not have either accounts, very popular failed uses and gratification included "they just have no desire to have an account" (70.3\%), "they are too busy" $(63.4 \%)$, "they think it is a waste of time" $(60.4 \%)$, "they think it is stupid" (55.4\%), "they have no Internet access at home" (51.5\%), and "they are not good at using technology" (34.7\%). Less commonly reported failed uses and gratifications included "they have not heard of these Web sites" (17.8\%), "they do not want to keep in touch" (15.8\%), "they are loners" $(10.9 \%)$, "they do not want to conform" $(7.9 \%)$, "they are not cool" $(7.9 \%)$, "they do not have any friends" (7.9\%), "they feel intimidated" (5.9\%), and "they think others would not be interested in their accounts" (5.0\%).

\section{Users: sex differences}

First, a MANOVA was conducted to determine the effect of sex of participant on the seven interval dependent variables related to general account information. The seven dependent variables were hours per day on your account, hours per day on 
others account, number of times per day logging into your account, days per week logging into account, changing appearance of account, updating account, and number of friends linked to account. Results indicated that sex significantly affected the combined dependent variables, Pillai's trace $=0.27$, $F(7,86)=4.43, p<0.001, \eta^{2}=.27$, power $=0.99$. Univariate ANOVAs were conducted as followup tests. ANOVA results indicated that number of times per day logging into your account significantly differed by sex $\left[F(1,92)=4.04, p<0.05, \eta^{2}=\right.$ 0.04 , power $=0.51]$ with men logging into their accounts more frequently than women (5.00 times per day versus 3.45); how often they changed the appearance of the Web site significantly differed by $\operatorname{sex}\left[F(1,92)=9.29, p<0.01, \eta^{2}=0.09\right.$, power $=$ 0.85 ] with women changing the appearance more often than men (3.38 on a 7-point Likert scale versus 2.26); and number of friends linked to account significantly differed by sex $[F(1,92)=5.18, p<$ $0.05, \eta^{2}=0.05$, power $\left.=0.62\right]$ with men reporting more friends linked to account than women (280.02 versus 193.28). Additionally, with regard to general account information, a series of a two-way contingency table analyses was conducted to evaluate whether men or women were more likely to make personal information available, make schedules available, set Web site to private, and know friends linked to the account. For each analysis, the two variables were sex of participant and level of agreement with the statement (i.e., yes and no). Results indicated that women $(63.5 \%)$ were significantly more likely than men $(38.8 \%)$ to set their Web site to private, $\chi^{2}(1, N=101)=6.16, p<0.05$.

Second, a series of a two-way contingency table analyses was conducted to evaluate whether men or women were more likely to engage in each of the uses and gratifications for having an account. The 11 dependent variables were to keep in touch with current friends, to keep in touch with old friends, to make new friends, to locate old friends, for dating purposes, to feel connected, to learn about events, to share information about yourself, to post/look at pictures, for academic purposes, and to post social functions. For each analysis, the two variables were sex of participant and level of agreement with the statement (i.e., yes and no). Results indicated that men $(16.3 \%)$ were significantly more like than women $(0.0 \%)$ to use the friend-networking sites for dating purposes $\left[\chi^{2}(1, N=101)=9.22, p<0.01\right]$ and men $(44.9 \%)$ were significantly more likely than women $(23.1 \%)$ to use the friend-networking sites to learn about events $\left[\chi^{2}(1, N=101)=5.38, p<0.05\right]$.

Third, a series of a two-way contingency table analyses was conducted to evaluate whether men or women were more likely to select failed uses and gratifications as reasons why others did not use friend-networking sites. The 14 dependent variables were they have not heard of these Web sites, they do not have Internet access at home, they are not good at using technology, they are too busy, they do not have any friends, they do not want to keep in touch, they are "loners," they think it is stupid, they are not cool, they feel intimated, they just have no desire to have an account, they do not want to conform, they think it is a waste of time, and they think others would not be interested in their accounts. For each analysis, the two variables were sex of participant and level of agreement with the statement (i.e., yes and no). Results indicated men $(30.6 \%)$ were significantly more likely than women $(5.8 \%)$ to select as a failed uses and gratification that others had not heard of these Web sites [ $\chi^{2}(1, N=$ $101)=10.63, p<0.001]$; women $(75.0 \%)$ were significantly more likely than men (51.0\%) to select that others are too busy $\left[\chi^{2}(1, N=101)=6.25, p<0.05\right]$; men $(14.0 \%)$ were significantly more likely than women $(1.9 \%)$ to select that others do not have any friends $\left[\chi^{2} \quad(1, N=101)=5.29, p<0.05\right]$; men $(18.4 \%)$ were significantly more likely than women $(3.8 \%)$ to select that others are "loners" [ $\chi^{2}(1, N=$ $101)=5.48, p<0.05]$; women $(82.7 \%)$ were significantly more likely than men $(57.1 \%)$ to select that others just have no desire to have an account $\left[\chi^{2}(1\right.$, $N=101)=7.89, p<0.01]$.

Finally, a MANOVA was conducted to determine the effect of sex on the five dependent variables related to feelings upon receiving a new message. The five dependent variables were: happy, excited, anxious, upset, and concern over terminated account. Results indicated that sex did not significantly affect the combined dependent variables.

Nonusers: general information, uses and gratifications, and sex differences

Of the participants surveyed, 15 or $12.9 \%$ (4 men and 11 women) indicated that they did not have either a MySpace or Facebook account. Most of the nonusers had not previously had accounts at either site $(86.7 \%)$, had heard of MySpace (86.7\%), and had heard of Facebook $(60.0 \%)$. Although the nonusers reported hearing other people frequently talk about these sites (mean of 5.20 on 7-point Likert scale from 1 , never, to 7 , all the time) and that the sites were relatively popular among their friends (mean of 5.17 on 7-point Likert scale from 1, not at all popular, to 7 , very popular), the nonusers reported feeling no pressure to get an account (mean of 2.40 on 7-point Likert scale from 1, not at all, to 7, very much), nor 
did they report feeling left out by not having an account (mean of 2.60 on 7-point Likert scale from 1, not at all, to 7 , very much). Although $60 \%$ of nonusers indicated that they had viewed someone else's account, only 33.3\% reported that they had considered getting an account in the future.

When examining the failed uses and gratifications for not having an account, the two most popular responses were "I just have no desire to have an account" (73.3\%) and "I am too busy" (46.7\%). Less frequently reported failed uses and gratifications included "I do not want other people to know about my personal business" (26.7\%), "I think it is a waste of time" (20.0\%), "I think it is unsafe" $(13.3 \%)$, "I do not have Internet access at home" $(13.3 \%)$, "I have not heard of these Web sites" $(6.7 \%)$, "I do not want to keep in touch" (6.7\%), and "I do not want to conform" (6.7\%). No participants reported not using the Web sites because "I am not good at technology," "I have not made many friends yet," "I feel intimidated," "I think it is stupid," and "I am a loner."

When asked to predict what uses and gratifications users obtained from the Web sites, nonusers most frequently listed "to keep in touch with friends/meet new people" (93.3\%). Other commonly reported uses and gratifications included "it is the thing to do" (46.7\%), "to be like others" $(40.0 \%)$, "to share information" $(40.0 \%)$, "to occupy time" $(40.0 \%)$, "to look cool" $(26.7 \%)$, "pressure from friends" $(20.0 \%)$, "to talk bad about other people" (13.3\%), and "I do not know/not sure" (6.7\%). Finally, MANOVA results indicated that general information about nonusers, failed uses and gratifications, and predicted uses and gratifications did not significantly differ by sex of participant.

\section{Nonusers versus users}

Results indicated two significant differences between users and nonusers in terms of demographics. First, users (19.05 years) were significantly chronologically younger than nonusers (24.80 years), $t(114)=-6.60, p=0.000$. In addition, a twoway contingency table analysis was conducted to evaluate whether different ethnic groups were more likely to use friend-networking sites. For this analysis, the two variables were ethnicity of participant (i.e., Hispanic, Caucasian, African American, Native American, and multiracial) and whether or not the participant had an account (i.e., yes and no). Results indicated a difference did exist among the ethnic groups, $\chi^{2}(4, N=116)=19.63, p<0.001$. Additional inspection of the data indicated that Native
Americans were less likely to be users than all other ethnic groups.

\section{DISCUSSION}

A large percentage $(87.1 \%)$ of participants indicated having a friend-networking account. This is impressive especially considering that no mention was made of friend-networking sites in the research project description made available to participants. It is possible that time of the year (spring semester) increased the number of participants having accounts and that the same study conducted with primarily freshman in the fall semester would have a lower percentage. Still, most participants indicated that they had had their accounts for 7 to 24 months, extending back past the start of the fall semester. In addition, it is important to note the number of college students using these sites and the amount of time per day students spend on these friend-networking sites. Specifically, students spend almost 3 hours per day either on their accounts or someone else's account. This number must also be considered in light of the fact that students having both MySpace and Facebook accounts were instructed to answer questions thinking of the account they used most frequently. That means that $74.3 \%$ of the participants devoted some additional time per day, on top of the 3 hours, to their other friend-networking account. One reason participants might be spending so much time per day on their accounts is the number of friends they have linked to their account. If participants are to interact with 200-plus friends per day, that requires substantial time!

When examining the characteristics of users, women and men were equally likely to have accounts at a friend-networking site. However, their uses and gratifications for doing so varied in some specific cases. A difference was found between users and nonusers with users being significantly younger than nonusers, supporting findings of previous research. ${ }^{6}$ This could be because younger users are more comfortable with online communication in general. A difference was also observed between users and nonusers with regards to ethnicity. Specifically, Native Americans participants were significantly less likely than Hispanic, Caucasian, African American, and multiracial participants to be users.

With so many college students using these friendnetworking sites and spending a significant amount of their time on them, users must be meeting personal and social needs from these sites. For example, popular uses and gratifications such as "to keep 
in touch with old friends," "to keep in touch with current friends," and "to make new friends" indicate that users are meeting a "friend" need. Similarly, uses and gratifications such as "to learn about events," "to post social functions," and "to feel connected" indicate that users are meeting a need by using the site as a source of information. Currently, the authors are gathering more data and using factor analysis to investigate what, if any, underlying constructs explain these uses and gratifications.

Sex differences did occur when comparing uses and gratifications for users. However, sex differences were not found for the most popular uses and gratifications, indicating that in general men and women meet the same needs by using the sites. A sex difference did occur with the number of friends linked to the account, with men having significantly more friends linked to their accounts than women. Developmental research ${ }^{19}$ notes similar findings with men reporting more friends than women throughout the lifespan.

Limitations of the current exploratory study include that primarily freshman college students were surveyed. Future research should investigate if the use of such friend-networking sites changes as students continue their degrees. A second limitation was the small number of nonusers. To better understand why individuals do not use these sites, more data from nonusers needs to be collected. In addition to investigating the underlying structures for the uses and gratifications, future research should examine the personality characteristics of users and nonusers. Finally, results indicated that Native American students were significantly less likely than all other ethnic groups to be users of friend-networking sites. Again, this result should bring forth further investigation.

\section{REFERENCES}

1. Lievrouw LA. Babel and beyond: languages on the Internet. ICA News 2000; 28:6-9.

2. Harris RJ. (2006). A cognitive psychology of mass communication, 4th ed. Mahwah, NJ: Erlbaum.

3. Kiesler S, ed. (1997). Culture of the Internet. Mahwah, NJ: Erlbaum.

4. Weiser E. Gender differences in Internet use patterns and Internet application preferences: a two-sample comparison. CyberPsychology \& Behavior 2000;4:167-78.

5. Howard P, Rainie L, Jones S. Days and nights on the Internet: the impact of diffusing technology. American Behavioral Scientist 2001; 45:450-72.
6. Thayer SE, Ray S. Online communication preferences across age, gender, and duration of Internet use. CyberPsychology \& Behavior 2006; 9:432-40.

7. CNN. (2006). MySpace cowboys. http://money.cnn. com/magazines/fortune/fortune_archive/2006/09/ 04/8384727/index.htm (accessed August 2006).

8. Foxnews. (2006). Angry students lash out at Facebook. com privacy changes. http://72.14.209.104/search?q= cache:G27bD-yC8BUJ:www.foxnews.com / story/0,293 (accessed September 2006).

9. Murphy D. A virtual student body: a behind-thescenes look at Facebook.com, the college world's most popular online social network. PC Magazine 2005; 82.

10. Valkenburg PM, Peter J, Schouten A. Friend networking sites and their relationship to adolescents' well-being and social self-esteem. CyberPsychology \& Behavior 2006; 9:584-90.

11. Papacharissi Z, Rubin, A. Predictors of Internet use. Journal of Broadcasting and Electronic Media 2000; 44:175-96.

12. Rubin AM. (2002). The uses and gratifications perspective of media effects. In Bryant J, Zillmann D, eds., Media effects: advances in theory and research, 2nd ed. Mahwah, NJ: Erlbaum, pp. 525-48.

13. Carey JW, Kreiling AL. (1974). Popular culture and uses and gratifications: Notes towards an accommodation. In Blumler JG, Katz E, eds., The uses of mass communications: current perspectives on gratification research. Beverly Hills, CA: Sage, pp. 225-48.

14. Elliot P. (1974). Uses and gratifications research: a critique and a sociological alternative. In Blumler JG, Katz E, eds., The uses of mass communications: current perspectives on gratification research. Beverly Hills, CA: Sage, pp. 249-68.

15. Anderson JA, Meyer TP. Functionalism and the mass media. Journal of Broadcasting 1975; 19:11-22.

16. Swanson DL. Political communication research and the uses and gratifications model: a critique. Communication Research 1979; 6:37-53.

17. Swanson DL. The uses and misuses of uses and gratifications. Human Communication Research 1977; 3:214-21.

18. Blumler JG. The role of theory in uses and gratifications studies. Communication Research 1979; 6:9-36.

19. Fehr B. (2000). The life cycle of friendship. In Hendrick C, Hendrick S, eds., Close relationships: a sourcebook. Thousand Oaks, CA: Sage, pp. 71-82.

Address reprint requests to: Dr. John Raacke Department of Psychology \& Counseling University of North Carolina at Pembroke One University Drive Pembroke, NC 28372

E-mail: john.raacke@uncp.edu 
Copyright of CyberPsychology \& Behavior is the property of Mary Ann Liebert. Inc. and its content may not be copied or emailed to multiple sites or posted to a listserv without the copyright holder's express written permission. However, users may print, download, or email articles for individual use. 